\title{
Development and validation of forensically useful growth models for Central European population of Creophilus maxillosus L. (Coleoptera: Staphylinidae)
}

\author{
Katarzyna Frątczak-Łagiewska ${ }^{1,2,3} \cdot$ Andrzej Grzywacz $^{4} \cdot$ Szymon Matuszewski ${ }^{1,2}$
}

Received: 21 October 2019 / Accepted: 12 March 2020 / Published online: 8 April 2020

(C) The Author(s) 2020 2020, corrected publication 2020

\begin{abstract}
The hairy rove beetle, Creophilus maxillosus (Linnaeus) (Staphylinidae), is recognized for its use in forensic entomology. However, insufficient developmental data exist for the Central European population of this species. Accordingly, we studied the development of $C$. maxillosus at ten constant temperatures $\left(10-32.5^{\circ} \mathrm{C}\right)$. Based on these results, linear and nonlinear developmental models were created and validated. We also studied the effect of different homogenous diets (third-instar larvae or puparia of Calliphora sp. Robineau-Desvoidy or Lucilia sp. Robineau-Desvoidy (Diptera: Calliphoridae) or mix of first- and second-instar larvae of Necrodes littoralis (Linnaeus) (Coleoptera: Silphidae)) on the development and mortality of $C$. maxillosus. Average total development times ranged between 122.21 days at $15^{\circ} \mathrm{C}$ and 22.18 days at $30^{\circ} \mathrm{C}$. Beetles reached the adult stage in seven out of ten temperatures $(15-$ $30^{\circ} \mathrm{C}$ ). No beetles reached the adult stage when fed with larvae of $N$. littoralis; their development times at first and second larval stage were also significantly longer than in other food conditions. When C. maxillosus larvae were fed with blowfly larvae, the highest mortality was observed at the pupal stage, as compared when they were fed with blowfly puparia — at the first larval stage. While validating thermal summation models, the highest age estimation errors were found for beetles bred at 10 and $12.5^{\circ} \mathrm{C}$ (between 21 and $43 \%$ for all developmental events). Age estimation errors were on average higher for pupation and eclosion than hatching and first and second ecdyses. While validating the models with specimens fed with different diets, the highest errors were recorded for beetles fed with $N$. littoralis larvae (22\% for the first ecdysis and 33\% for the second ecdysis) and Lucilia sp. puparia (32\% for pupation and $22 \%$ for eclosion). Implications for C. maxillosus use in forensic entomology are discussed.
\end{abstract}

Key Points

- Development of the Central European population of C. maxillosus was studied at ten constant temperatures and using different homogenous diets.

- Thermal summation models were validated with insects reared at different temperatures and fed with different diets.

- Total development times ranged between 122 days at $15{ }^{\circ} \mathrm{C}$ and 22 days at $30{ }^{\circ} \mathrm{C}$. Beetles reached the adult stage in seven temperatures $\left(15-30{ }^{\circ} \mathrm{C}\right)$.

- The highest age estimation errors were found for beetles bred at 10 and $12.5^{\circ} \mathrm{C}(21-43 \%)$ and for beetles fed with Necrodes littoralis larvae (22-33\%).

- The lowest mortality was observed for beetles fed with Calliphora sp. and Lucilia sp. larvae. Estimation errors were generally low for beetles fed with blowfly larvae or Calliphora sp. puparia.

Keywords Forensic entomology $\cdot$ Developmental models $\cdot$ Creophilus maxillosus $\cdot$ Staphylinidae $\cdot$ Minimum postmortem interval · Validation study

Electronic supplementary material The online version of this article (https://doi.org/10.1007/s00414-020-02275-3) contains supplementary material, which is available to authorized users.

Katarzyna Frątczak-Łagiewska

katarzyna.fratczak@amu.edu.pl

1 Laboratory of Criminalistics, Adam Mickiewicz University, Św. Marcin 90, 61-809 Poznań, Poland

2 Centre for Advanced Technologies, Adam Mickiewicz University, Uniwersytetu Poznańskiego 10, 61-614 Poznań, Poland
3 Department of Animal Taxonomy and Ecology, Adam Mickiewicz University, Uniwersytetu Poznańskiego 6, 61-614 Poznań, Poland

4 Department of Ecology and Biogeography, Faculty of Biological and Veterinary Sciences, Nicolaus Copernicus University, Lwowska 1, 87-100 Toruń, Poland 


\section{Introduction}

Development time of insects depends mostly on temperature $[1,2]$. Poikilotherms operate within species-specific temperature ranges associated with their local temperatures. Development beyond these limits may be harmful or even lethal for them $[3,4]$. Predicted thermal tolerance for development of insects, the range in temperature between the minimum and the maximum rate of development, is about $20^{\circ} \mathrm{C}$ [5]. Thermal development of insects is a powerful tool in forensic entomology. Insect development models may be used to estimate the minimum time that elapsed from death until the body discovery (called min PMI) [2]. This involves estimating the age of the oldest immature insects found on a cadaver based on age indicators such as development stage or larval length [2]. The possibility to use the method depends on the availability of developmental data for the species collected on a crime scene. Observed values of insect age indicators are compared with the reference developmental data. Such data are collected during laboratory experiments where the development of insects is studied under controlled conditions [6]. Results of such experiments are presented using graphical development representations (i.e., isomegalen and isomorphen diagrams) or mathematical development models (i.e., linear or nonlinear development equations) [7].

Developmental data used in forensic entomology are collected using different insect rearing protocols, sampling frequency, sample sizes, killing or preservation techniques etc. As a consequence, the data used in casework may differ in quality with likely detrimental effects on the accuracy or precision of min PMI estimates [8]. The ideal reference data should accurately reflect the development of insects on cadavers under natural conditions. However, developing such perfect reference data in the laboratory is simply impossible. Therefore, all data used by forensic entomologists in casework have limitations resulting from their laboratory origin. Currently, one of the most pressing needs of forensic entomology is to identify factors affecting the quality of reference developmental data and to determine the magnitude of their impact.

Insect development was analyzed and modeled in different ways in forensic entomology [9]. In most cases, linear development models were used, i.e., simple regression model relating developmental rate with rearing temperature [2] or the thermal summation model sensu Ikemoto and Takai [10] (e.g., [11-16]). Although frequently used in insect developmental studies, nonlinear models were developed less frequently in forensic entomology-oriented experiments (but see [9, 17-19]). Although they describe the relationship more accurately than linear models, they are less practically useful as they do not provide thermal constant $K$ for the developmental landmarks [17]. The constant $K$ for a landmark may be divided into smaller parts, enabling retrospective calculation of the time needed to reach the landmark in changing temperature conditions. Moreover, it may be used to estimate the age of the most problematic pieces of insect evidence, i.e., postfeeding larvae or pupae, through subtracting thermal units which insects collected on a crime scene have accumulated in the laboratory from the constant $K$ [20]. The thermal constants may be estimated using different methods and from different data. Accordingly, they may represent the true thermal constants for an insect population with different accuracy. For this reason, it is necessary to validate thermal constants or any other reference developmental data used by forensic entomologists [21]. Some validation studies in forensic entomology revealed low accuracy of the laboratory-produced data when applied to insects reared in naturally occurring temperatures [21]. Although there are different ways to validate reference developmental data [21-25], the minimum standard should be a validation using insect laboratory sample different than the one used for the derivation of the data.

Another group of factors affecting the quality of developmental data is related to laboratory protocols, e.g., methods of larval measurement, conditions of insect colony maintenance, or food quality and quantity [26]. Food quality influences the survival and development of insects in nature [27]. Its effect on the development was demonstrated in several species of necrophagous flies [21, 28-32]. No previous work tested such effects in forensically useful insect predators. Prey quality has a direct impact on growth and development of predatory insects $[33,34]$. It is not clear what exactly predatory beetle species (e.g., staphylinids or histerids) eat on carrion. Based on the literature $[35,36]$, they should prey mostly on larvae and puparia of blowflies. However, their food preferences have not been investigated. Moreover, it is possible that food type affects their development. Consequently, in casework, the accuracy of insect age estimation may be reduced by using developmental data derived from insects fed with non-optimal food type.

Creophilus maxillosus (Linnaeus) (Coleoptera: Staphylinidae) is a common predator of fly larvae and puparia associated with carrion [7, 37]. It abundantly visits and breeds in large vertebrate cadavers and is recognized as highly forensically useful [38-41]. Early works analyzed the development of C. maxillosus in uncontrolled rearing conditions [42, 43]. Watson-Horzelski [44] investigated the development of C. maxillosus at 3 temperatures for the population from Southern United States. Wang et al. [45] provided more robust development models of the species for the population from China. However, distinct populations may respond differently to similar environmental conditions. Thus, to get accurate insect age estimates, calculations should use developmental data for the local insect population $[17,46]$. Recently more attention has been paid to the Central European population of C. maxillosus [7, 8, 47]. Differences in development time 
between males and females of $C$. maxillosus were reported, however with no significant influence on the accuracy of age estimates using sex-specific as compared with general thermal summation models [7]. Creophilus maxillosus size at emergence was demonstrated to be useful for physiological age prediction and accordingly for the improvement of the age estimate accuracy in forensic entomology [47]. Moreover, it was found that the multiple measurement protocol affects the accuracy of insect age estimates using the resultant reference developmental data [8]. However, none of these studies derived developmental models for all developmental landmarks of Central European C. maxillosus.

Consequently, the aim of this study was to create full set of developmental models for the central European population of C. maxillosus and to validate the models with insects reared at different temperature conditions and fed with different diets. Additionally, we investigated how different homogenous diets affect development and mortality of $C$. maxillosus.

\section{Materials and methods}

\section{Insect colony establishment and maintenance}

Insects were collected from rabbit carcasses placed in a xerothermic grassland (Biedrusko military range, western Poland: $\left.5231^{\prime} \mathrm{N}, 1655^{\prime} \mathrm{E}\right)$. Carcasses were exposed in spring and summer of 2015 and 2016 every few days to have permanent access to adult beetles. Beetles were collected during 5-7 inspections each year, 10-15 specimens at a time. A colony consisted of 25-30 individuals with a more or less equal proportion of males and females. New beetles sampled in the field and first generations bred in the laboratory were used to permanently renew the colony. Adult beetles were kept in plastic containers $(30 \times 20 \times 20 \mathrm{~cm})$ with $6-7 \mathrm{~cm}$ layer of moist soil and access to water. They were fed once a day with a mix of blowfly third-instar larvae and puparia. Containers were kept at room temperature $\left(20-22{ }^{\circ} \mathrm{C}\right)$ and humidity $(50-60 \%)$ and cleaned once a week to avoid the appearance of mites and mold.

\section{Methods common for temperature and food type experiments}

\section{Rearing}

Females of C. maxillosus lay singular eggs in small clumps of soil which makes them difficult to be found. Eggs in the same age were obtained by placing adult insects from a single colony into 3-1 container filled halfway with soil for $4 \mathrm{~h}$. Containers were kept in the dark at a room temperature (20$22{ }^{\circ} \mathrm{C}$ ). Afterwards, adult beetles were pulled out and containers were placed in insect incubators (ST 1/1 BASIC or +,
POL-EKO, Poland) set for the specific temperature. After $70 \%$ of the average egg stage duration, containers were inspected for the presence of first-instar larvae at intervals equal to $10 \%$ of the average egg stage duration. Freshly hatched first-instar larvae are creamy-white and very active, so it is easy to find them while searching the soil. Only freshly hatched larvae were sampled and transferred to separate cups.

First- and second-instar larvae were kept in $80-\mathrm{ml}$ containers filled with $1.5 \mathrm{~cm}$ of soil. Third-instar larvae, immediately after the second ecdysis, were transferred to $120-\mathrm{ml}$ containers with 5-6 cm of soil and were kept there until adults emerged. Containers were placed in insect incubators (ST 1/1 BASIC or + , POL-EKO, Poland). Humidity in incubators was maintained at 60-70\% and a photoperiod (h) was set on 12:12 (L:D).

\section{Inspections and measurements}

All individuals were inspected for developmental landmarks: hatching, first and second ecdysis, pupation, adult emergence. After $60 \%$ of the average stage duration, insects were checked every $10 \%$ of stage duration. Containers were taken out of the incubator, and beetles were inspected for developmental stage. In each stage, 4-5 inspections were made. After noticing the landmark, the midpoint between current and previous inspection was used as the actual time of the landmark occurrence. Transitions between larval stages were determined based on the creamy-white color of a larva (appearing shortly after ecdysis) and the width of the mesonotum.

A geometrical micrometer was used to measure in vivo larval length. The larva was placed in a $1.5-\mathrm{ml}$ Eppendorf tube, and after it had become immobile and fully erected, its length (from clypeus to the last abdominal segment) was measured with a micrometer. The analytical balance AS 82/ 220.R2 (Radwag, Poland) was used to weigh larvae and pupae in a 1.5-ml Eppendorf tube.

\section{Experiment 1: Effect of temperature on development}

Development was studied at ten constant temperatures: 10 $32.5^{\circ} \mathrm{C}$, in $2.5^{\circ} \mathrm{C}$ intervals. Two or three temperatures were studied at the same time. Larvae were fed once a day with third-instar larvae of blowflies punctured to make feeding easier for the first- and second-instar larvae of C. maxillosus.

Forty larvae per temperature were used. Insects were randomly allocated to temperatures. All individuals were inspected for developmental landmarks. Twenty individuals were also repeatedly measured and weighted. Containers were placed on two shelves inside the incubator. Container positions were rearranged every few inspections.

Inspection intervals were calculated based on the results of pilot tests at 5 temperatures $\left(12.5,17.5,22.5,27.5,32.5^{\circ} \mathrm{C} ; 10\right.$ insects per temperature). Intervals established at a specific 
temperature were also used for the lower adjoining temperature (e.g., intervals at $12.5^{\circ} \mathrm{C}$ were also used for $10^{\circ} \mathrm{C}$ ).

Differences in mortality between specimens bred at different temperatures were evaluated using the chi-squared test. Percentage mortality was defined as [(number of dead specimens $\times 100 \%)$ /number of sampled larvae]. Differences in time of development and differences in length or weight between specimens bred at different temperatures were evaluated using one-way analysis of variance. All analyses were conducted using Statistica 13.1 (StatSoft).

Models for particular developmental events were developed using data for randomly selected non-measured beetles (usually 10 per temperature), chosen for each model from the entire insect pool. We derived the linear Ikemoto and Takai model [10] (Eq. 1) and nonlinear models: Analytis [48] (Eq. 2), Brière-2 [49] (Eq. 3), Lactin-2 [50] (Eq. 4), and SSI (Sherpe-Schoolfield-Ikemoto) [51] (Eq. 5).

$D T=k+T_{\min } D$

where $D$ is the duration of development (in hours or days), $T$ is the rearing temperature, $T_{\min }$ is the lower developmental threshold, and $k$ is thermal summation constant. It is recommended to calculate these parameters by means of the reduced major axis (RMA) instead of the ordinary least squares (OLS) regression $[10,17]$. Model was calculated with the lmodel 2 package [52] in $R$, where the RMA is called a standard major axis (SMA) regression.

$$
\begin{aligned}
& \frac{1}{D}=a \times\left(T-T_{\min }\right)^{n} \times\left(T_{\max }-T\right)^{m} \\
& \frac{1}{D}=a \times\left(T-T_{\min }\right) \times\left(T_{\max }-T\right)^{\frac{1}{d}} \\
& \frac{1}{D}=e^{(p \times T)}-e^{\left(p \times T_{\max }-\left(\frac{T_{\max }-T}{\Delta T}\right)\right)}+\lambda \\
& \frac{1}{D}=\frac{\rho_{\varphi}\left(\frac{T}{T_{\varphi}}\right) \times e^{\left[\frac{\Delta H_{\mathrm{A}}}{R} \times\left(\left(\frac{1}{T_{\varphi}}\right)-\left(\frac{1}{T}\right)\right)\right]}}{1+e^{\left[\frac{\Delta H_{\mathrm{L}}}{R} \times\left(\left(\frac{1}{T_{\mathrm{L}}}\right)-\left(\frac{1}{T}\right)\right)\right]}+e^{\left[\frac{\Delta H_{\mathrm{H}}}{R} \times\left(\left(\frac{1}{T_{\mathrm{H}}}\right)-\left(\frac{1}{T}\right)\right)\right]}}
\end{aligned}
$$

where $1 / D$ is development rate, $T$ is the rearing temperature, $T_{\min }$ is the lower developmental threshold, and $T_{\max }$ is the upper developmental threshold [53]. In the Analytis model $a, n$, and $m$ are constants $[48,54]$. In the Brière-2 model, $a$ and $d$ are empirical constants $[49,55]$. In the Lactin-2 model, $p$ is a constant defining rate of optimum temperature, $\Delta T$ is the temperature range across which physiological breakdown becomes the overriding influence, and $\lambda$ allows the curve to intercept the $x$-axis allowing the estimation of lower temperature threshold $\left(T_{\min }\right)[50,54]$. In the SSI model, $\rho_{\varphi}$ is the development rate at the intrinsic optimum temperature $T_{\varphi}$, $\Delta H_{\mathrm{A}}$ is the change in enthalpy of activation of the reaction that is catalyzed by the enzyme, $\Delta H_{\mathrm{L}}$ is the change in enthalpy associated with low temperature inactivation of the enzyme, and $\Delta H_{\mathrm{H}}$ is the change in enthalpy associated with high temperature inactivation of the enzyme, $R$ is the gas constant (1.987 cal $/ \mathrm{deg} / \mathrm{mol}), T_{\mathrm{L}}$ is the temperature at which the enzyme is $1 / 2$ active and $1 / 2$ low temperature inactive, and $T_{\mathrm{H}}$ is the temperature at which the enzyme is $1 / 2$ active and $1 / 2$ high temperature inactive (both in Kelvin degrees) [51, 53].

Fitting of the nonlinear Analytis, Brière-2, and Lactin-2 models was done using the Levenberg-Marquardt algorithm with the minpack.Im package [56] and the SSI model using the SSI package [51], both in $R$.

\section{Experiment 2: Effect of food type on development}

For the experiment, we chose five different types of food, i.e., third-instar larvae of Calliphora sp. Robineau-Desvoidy and Lucilia sp. Robineau-Desvoidy (Diptera: Calliphoridae), puparia of Calliphora sp. and Lucilia sp., mix of first- and second-instar larvae of Necrodes littoralis (Linnaeus) (Coleoptera: Silphidae), as they are present on carrion at the same time as larval stages of $C$. maxillosus [57]. In these food type conditions, we reared 25,20,20,25, and 20 larvae of C. maxillosus, respectively. Third-instar larvae of blowflies were purchased from a fishing shop. Genus determinations were made using the identification key by Szpila [58]. In order to get puparia, larvae were bred in the laboratory. First- and second-instar larvae of $N$. littoralis were sampled from our laboratory colony.

Development was studied under constant temperature conditions of $24{ }^{\circ} \mathrm{C}$. Larvae were fed once a day ad libitum. All beetles were inspected for developmental landmarks. Additionally, third-instar larvae were measured and weighed at the beginning of the third larval stage and pupae were weighed at the beginning of the pupal stage.

Differences in mortality between specimens fed with different types of food were evaluated using the chi-squared test. Percentage mortality was defined as [(number of dead specimens $\times 100 \%) /$ number of sampled larvae]. Differences in time of development and differences in length or weight between specimens fed with different types of food were evaluated using one-way analysis of variance. All analyses were conducted using the Statistica 13.1.

\section{Validation of development models}

Models for particular developmental events were validated using different number of specimens originating from different temperature ranges, i.e., for hatching-241 specimens bred at $10-32.5{ }^{\circ} \mathrm{C}$, for first ecdysis -77 specimens bred at $12.5-32.5{ }^{\circ} \mathrm{C}$, for second ecdysis -75 specimens bred at $12.5-32.5{ }^{\circ} \mathrm{C}$, for pupation-46 specimens bred at 17.5 $30{ }^{\circ} \mathrm{C}$, and for eclosion -29 beetles bred at $20-27.5^{\circ} \mathrm{C}$. Due to large mortality at extreme temperatures, some of them were poorly represented or not represented in the validation sample. 
Models were also validated using beetles fed with different food types from our experiment 2, with 104, 102, 100, 82, and 72 beetles respectively for hatching, first ecdysis, second ecdysis, pupation, and eclosion.

The validation included a comparison of the thermal units needed to reach a particular developmental landmark with the thermal constant from the model. For this purpose, we calculated absolute differences between actual and model thermal units and divided them by actual thermal units.

\section{Results}

\section{Development of $C$. maxillosus across temperatures}

Mortality significantly varied across the temperatures $\left(\chi^{2}=\right.$ $420.0579, P<0.001$; Fig. 1). No beetle reached the adult stage at $10,12.5$, and $32.5^{\circ} \mathrm{C}$. The lowest mortality was at $25^{\circ} \mathrm{C}$ (Fig. 1). The highest mortality was recorded for third-instar larvae and pupae (Fig. 1). Mortality of third-instar larvae was the highest at low and high extreme temperatures, whereas pupae revealed an increase in mortality with increase in temperature (Fig. 1).

Beetles reached the adult stage in seven out of ten temperatures $\left(15-30^{\circ} \mathrm{C}\right)$ (Table 1, Figs. 1 and 2). Total development time ranged between 122.21 days at $15^{\circ} \mathrm{C}$ and 22.18 days at $30{ }^{\circ} \mathrm{C}$ (Table 1). At 10 and $12.5^{\circ} \mathrm{C}$, most larvae died in the postfeeding phase (Table 1, Figs. 1 and 2). At $32.5^{\circ} \mathrm{C}$, most larvae pupated but then pupae died (Table 1, Figs. 1 and 2). Fresh pupae reared at 30 and $32.5^{\circ} \mathrm{C}$ often failed to shed the third-instar exuvia.
Larval size, pupal weight, and adult size differed significantly between temperatures (larval length $F_{9.164}=$ 13.267, $P<0.001$, larval weight $F_{9.164}=26.944$, $P<0.001$, pupal weight $F_{7.95}=22.188, P<0.001$, adult length $F_{6.81}=13.243, P<0.001$, adult weight $F_{6.81}=$ $11.777, P<0.001$; Table 2). The largest size of pupae and adult beetles was recorded at $17.5^{\circ} \mathrm{C}$, and then, beetle size decreased with temperature (Table 2). Larval size changed similarly; however, the largest larvae were reared at $15{ }^{\circ} \mathrm{C}$ (Table 2).

\section{Differences in the development of $C$. maxillosus fed with different types of food}

Mortality significantly varied between types of food $\left(\chi^{2}=\right.$ $131.4858, P<0.001$; Fig. 3 ). No beetles reached the adult stage when fed with larvae of $N$. littoralis (Fig. 3). The lowest mortality was observed for beetles fed with Calliphora sp. and Lucilia sp. larvae (Fig. 3). In the case of beetles fed with blowfly puparia, the highest mortality was observed for first-instar larvae (Fig. 3). In the case of beetles fed with blowfly larvae, the highest mortality was observed at the pupal stage (Fig. 3).

First- and second-instar larvae of C. maxillosus fed with $N$. littoralis larvae developed significantly longer than beetles fed with other types of food (first instar $F_{4.89}=87.38, P<0.001$; second instar $F_{4.86}=228.79, P<0.001$; Fig. 4). Total development time was the shortest when $C$. maxillosus were fed with Lucilia sp. puparia $\left(F_{3.68}=13.166, P<0.001\right.$; Fig. 4).

Length and weight of third-instar larvae were the lowest when they were fed with Necrodes littoralis larvae (length $F_{4.85}=59.456, P<0.001$, weight $F_{4.85}=44.607, P<0.001$;
Fig. 1 Mortality of C. maxillosus developmental stages at different rearing temperatures

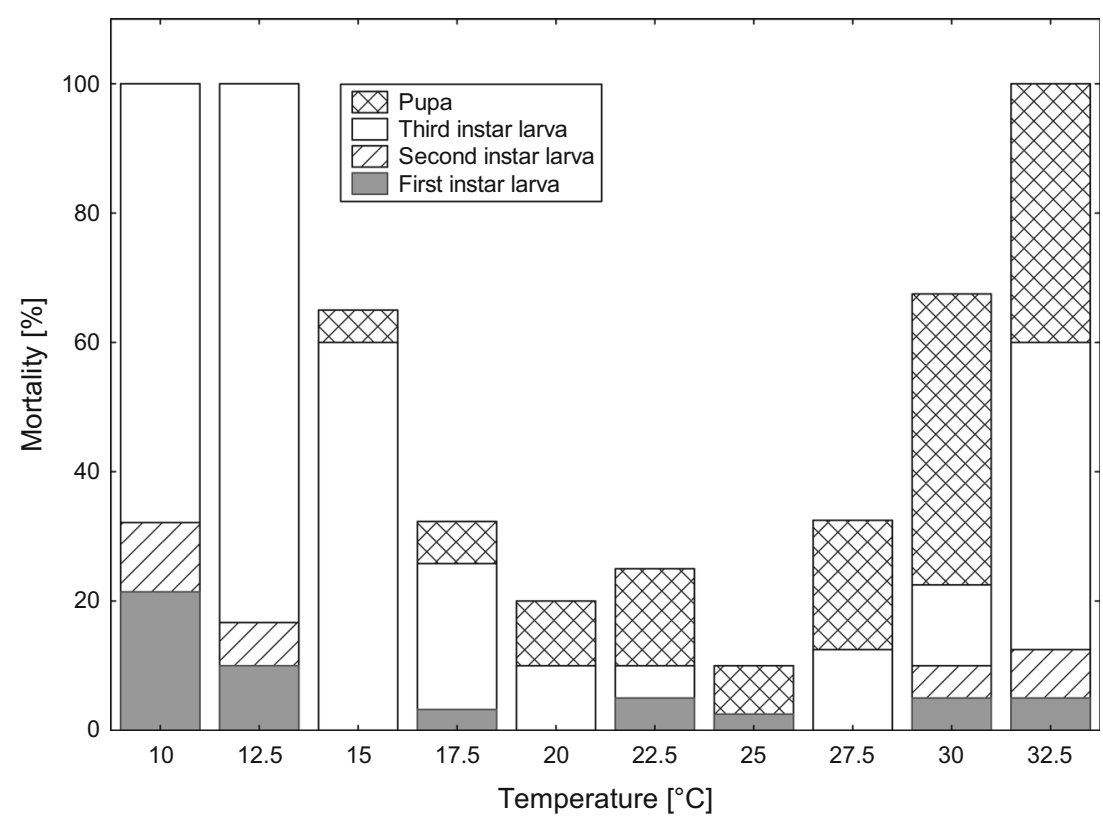


Table 1 Time of development (mean $(\mathrm{SE} ; N)$ ) of $C$. maxillosus at 10 constant temperatures. Mean for the egg stage duration was calculated on the basis of measured and non-measured individuals. For other stages, mean was calculated using only non-measured individuals

\begin{tabular}{lrlllll}
\hline Temperature $\left({ }^{\circ} \mathrm{C}\right)$ & \multicolumn{1}{l}{ Egg } & 1st-instar larva & 2nd-instar larva & 3rd-instar larva & Pupa & Total development \\
\hline 10 & $22.9(0.24 ; 19)$ & $12.9(0.54 ; 9)$ & $14.06(0.27 ; 8)$ & - & - & - \\
12.5 & $16.58(0.18 ; 25)$ & $8.92(0.14 ; 13)$ & $9.89(0.22 ; 14)$ & - & - & - \\
15 & $8.41(0.04 ; 40)$ & $4.99(0.1 ; 20)$ & $5.09(0.12 ; 20)$ & $67.74(10.81 ; 5)$ & $24.97(1.83 ; 5)$ & $122.21(6.63 ; 4)$ \\
17.5 & $5.9(0.08 ; 29)$ & $4.05(0.14 ; 14)$ & $4.34(0.12 ; 14)$ & $42.74(4.51 ; 11)$ & $19.11(0.43 ; 10)$ & $76.88(4.99 ; 10)$ \\
20 & $4.29(0.02 ; 40)$ & $2.65(0.04 ; 20)$ & $3.12(0.07 ; 19)$ & $18.4(0.5 ; 19)$ & $15.51(0.21 ; 17)$ & $43.91(0.57 ; 17)$ \\
22.5 & $3.33(0.03 ; 40)$ & $2.28(0.07 ; 18)$ & $2.46(0.08 ; 18)$ & $17.74(0.62 ; 16)$ & $12.25(0.19 ; 13)$ & $37.63(0.58 ; 13)$ \\
25 & $2.82(0.02 ; 37)$ & $1.86(0.04 ; 20)$ & $2.32(0.04 ; 20)$ & $13.8(0.38 ; 20)$ & $9.57(0.17 ; 18)$ & $29.91(0.74 ; 18)$ \\
27.5 & $2.58(0.02 ; 40)$ & $1.62(0.04 ; 19)$ & $2.08(0.05 ; 19)$ & $13.66(0.49 ; 17)$ & $8.07(0.25 ; 13)$ & $27.64(0.48 ; 13)$ \\
30 & $2.18(0.02 ; 36)$ & $1.38(0.02 ; 17)$ & $1.66(0.08 ; 17)$ & $10.56(0.47 ; 16)$ & $7.48(0.16 ; 8)$ & $22.18(0.42 ; 7)$ \\
32.5 & $2.1(0.02 ; 35)$ & $1.33(0.03 ; 17)$ & $1.78(0.04 ; 17)$ & $9.02(0.58 ; 6)$ & - & - \\
\hline
\end{tabular}

Table 3). Pupal and adult length and weight were the highest when larvae were fed with Calliphora sp. puparia; the differences between beetles fed with different blowfly-related food types were however insignificant (pupal weight $F_{3.69}=$ $1.0929, P=0.35805$; adult length $F_{3.63}=0.30579, P=$ 0.82110 ; adult weight $F_{3.63}=1.2683, P=0.29293$; Table 3).

\section{Development models}

All temperature points were included while calculating linear model parameters for developmental events (Fig. 5). Lower developmental thresholds calculated from linear model ranged from $8.085 \pm 0.365{ }^{\circ} \mathrm{C}$ for the second ecdysis to $11.98 \pm$

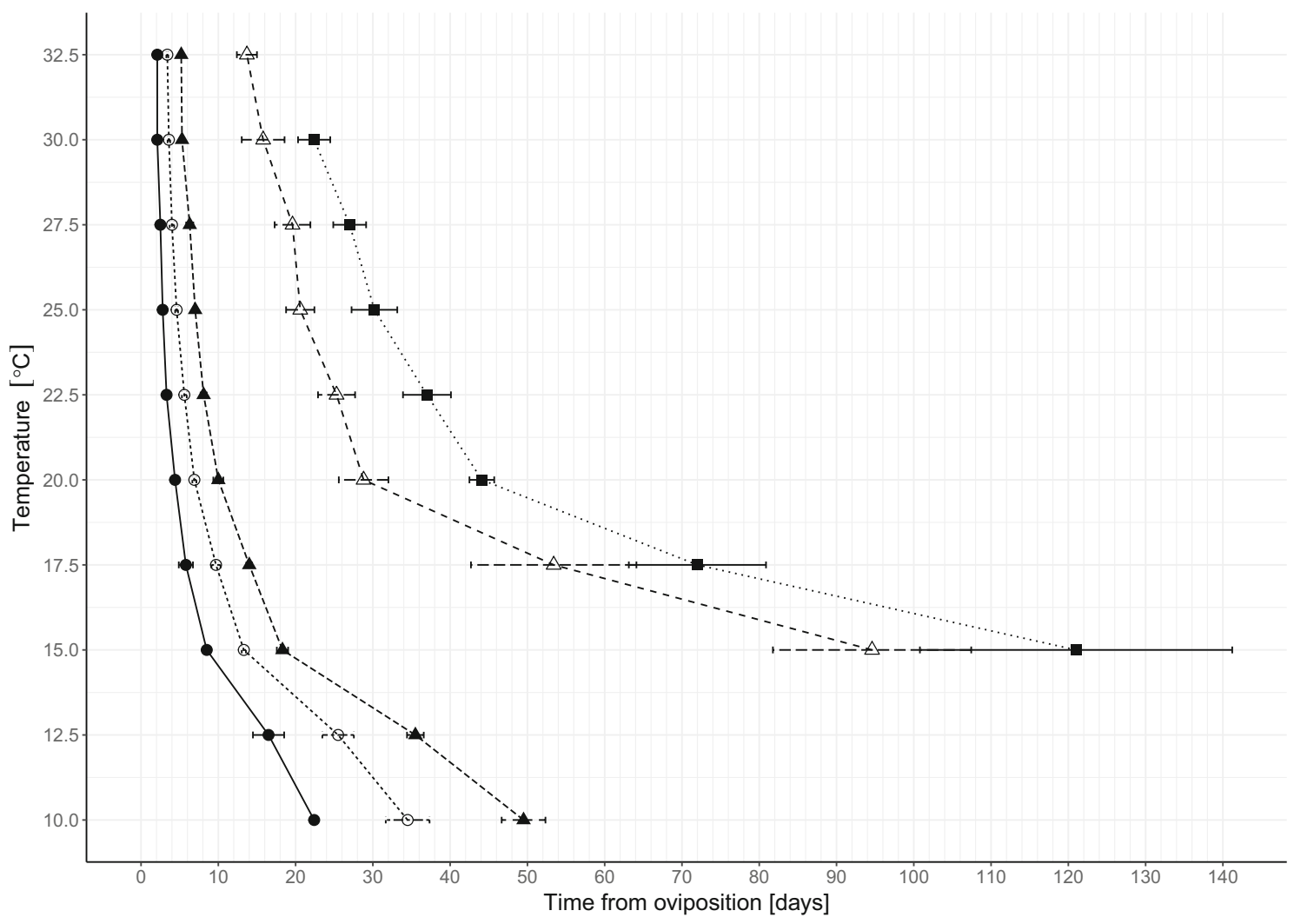

Fig. 2 Isomorphen diagram for C. maxillosus based on median times to reach particular developmental events at each of the rearing temperature conditions. Horizontal bars represent interquartile ranges. Areas between lines represent developmental stages; symbols represent developmental events. Black circle-hatching. White circle-first ecdysis. Black triangle — second ecdysis. White triangle - pupation. Black squareeclosion 
Table 2 Length and weight (mean $(\mathrm{SE} ; N)$ ) of $C$. maxillosus bred at different temperatures. Means were calculated based on the length and weight measurements conducted at the beginning of particular stage

\begin{tabular}{llllll}
\hline Temperature $\left({ }^{\circ} \mathrm{C}\right)$ & 3rd-instar length & 3rd-instar weight & Pupal weight & Adult length at emergence & Adult weight at emergence \\
\hline 10 & $16.85(0.21 ; 10)$ & $45.91(1.97 ; 10)$ & - & - & - \\
12.5 & $18.29(0.32 ; 12)$ & $56.67(2.79 ; 12)$ & - & - & - \\
15 & $20.53(0.36 ; 20)$ & $74.83(2.82 ; 20)$ & $177.9(3.69 ; 12)$ & $19.67(0.58 ; 9)$ & $147.69(4.29 ; 9)$ \\
17.5 & $20.28(0.29 ; 16)$ & $69.72(2.68 ; 16)$ & $185.01(6.63 ; 11)$ & $21.1(0.39 ; 10)$ & $158.83(6.01 ; 10)$ \\
20 & $19.88(0.26 ; 20)$ & $65.14(1.48 ; 20)$ & $160.86(4.47 ; 16)$ & $20.9(0.34 ; 15)$ & $140.73(4.14 ; 15)$ \\
22.5 & $19.78(0.29 ; 20)$ & $62.88(2.65 ; 20)$ & $148.16(4.83 ; 19)$ & $19.65(0.35 ; 17)$ & $127.72(3.95 ; 17)$ \\
25 & $19.39(0.12 ; 19)$ & $60.06(1.19 ; 19)$ & $146.7(3.06 ; 19)$ & $18.11(0.26 ; 18)$ & $124.65(2.6 ; 18)$ \\
27.5 & $18.6(0.29 ; 20)$ & $51.07(1.83 ; 20)$ & $130.45(5.25 ; 15)$ & $17.61(0.45 ; 14)$ & $114.57(8.04 ; 14)$ \\
30 & $19.13(0.44 ; 19)$ & $48.87(1.88 ; 19)$ & $110.16(5.23 ; 10)$ & $17.5(0.59 ; 5)$ & $94.56(2.48 ; 5)$ \\
32.5 & $17.5(0.25 ; 18)$ & $38.18(2.05 ; 18)$ & - & - & -
\end{tabular}

$0.351{ }^{\circ} \mathrm{C}$ for the pupation (Table 4). Although lower development threshold calculated from linear model was slightly below $12{ }^{\circ} \mathrm{C}$, beetles failed to reach the adult stage already at $12.5^{\circ} \mathrm{C}$. Estimated thermal summation constants required to reach certain developmental events are presented in Table 4.

In general, upper developmental thresholds were higher and lower developmental thresholds were lower when estimated with the Analytis, Brière-2, and Lactin-2 nonlinear models (Online Resource 1 and 2). Moreover, for pupation and eclosion, parameters of nonlinear models showed unrealistically high values of $T_{\max }$, reaching up to $185.8^{\circ} \mathrm{C}$ (Online Resource 1). The SSI model provided more reliable parameter values, and the estimated intrinsic optimum temperature, $T_{\varphi}$, ranged from 18.71 to $20.96{ }^{\circ} \mathrm{C}$. Lower developmental thresholds $T_{\min }$ calculated from linear model and $T_{\mathrm{L}}$ calculated from the SSI model were highly congruent (Tables 4 and 5). Values of $T_{\mathrm{H}}$ calculated using the SSI model ranged from $32.35{ }^{\circ} \mathrm{C}$ for hatching to $35.03{ }^{\circ} \mathrm{C}$ for pupation (Table 5, Fig. 6).

\section{Validation}

The highest errors were recorded for beetles bred at low temperatures, i.e., for all developmental event errors were between 21 and $43 \%$ (Fig. 7). Starting from $15{ }^{\circ} \mathrm{C}$, mean error rates were usually below $10 \%$ (Fig. 7). Mean error rates were higher for pupation and eclosion than those for hatching and first and second ecdyses $\left(F_{4.25}=16.421, P=0.00000\right.$; Fig. 7).

The highest errors were recorded for beetles fed with $N$. littoralis larvae (22\% for the first ecdysis and $33 \%$ for the second ecdysis) (Fig. 8). High error rates were also recorded for beetles fed with Lucilia sp. puparia (32\% for pupation and $22 \%$ for eclosion) (Fig. 8).
Fig. 3 Mortality of C. maxillosus developmental stages reared at $24{ }^{\circ} \mathrm{C}$ and fed with different food types

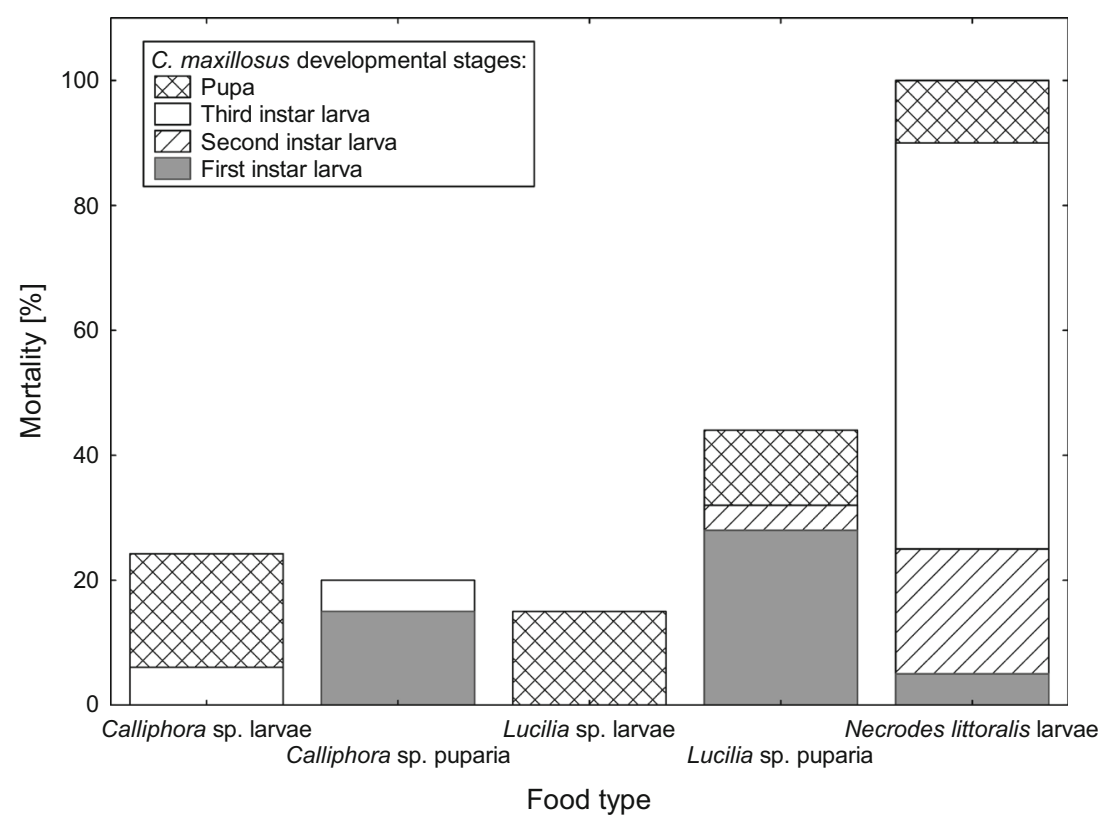


Fig. 4 Duration of C. maxillosus developmental stages reared at $24{ }^{\circ} \mathrm{C}$ and fed with different food types. Vertical bars represent standard errors; symbols represent mean developmental times of different instars

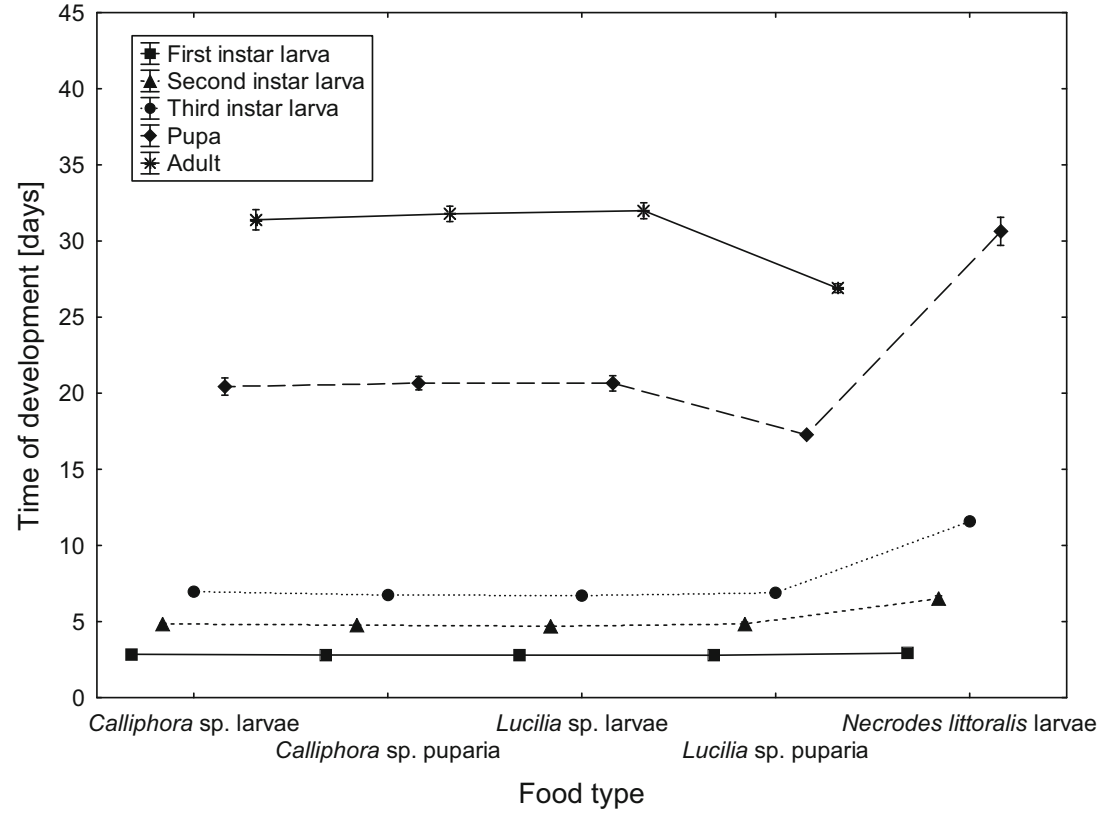

\section{Discussion}

We found that immature stages of $C$. maxillosus reached the adult stage in seven out of ten rearing temperatures (15$30{ }^{\circ} \mathrm{C}$ ). The thermal requirements for $C$. maxillosus development have previously been investigated for populations from China [45] and Southern United States [44]. Wang et al. [45] investigated the development at the temperature range 17.5$32.5^{\circ} \mathrm{C}$ and $C$. maxillosus reached the adult stage at all temperatures. Development times from oviposition to adult emergence for $C$. maxillosus in the present study were similar to these reported by Wang et al. [45]. The differences were found only at $17.5^{\circ} \mathrm{C}$ and $20^{\circ} \mathrm{C}$. Total development time at $16^{\circ} \mathrm{C}$ from Watson-Horzelski's study [44] was half shorter (65.47 days) than in the present study (122.21 days at $15^{\circ} \mathrm{C}$ ). It is possible that these large differences are a result of the shift in the linear portion of the relation between temperature and rate of development. Perhaps in the case of the C. maxillosus population from the USA, $16{ }^{\circ} \mathrm{C}$ lies within the liner portion of the relationship, whereas in the case of the European population of C. maxillosus, $15^{\circ} \mathrm{C}$ lies beyond this portion. Consequently, at the same low temperatures, Central
European beetles should develop longer than beetles from the USA. In the current study, no specimen reached the adult stage when bred at $32.5^{\circ} \mathrm{C}$. At the same temperature, Wang et al. [45] and Watson-Horzelski [44] obtained adult specimens. It is probably due to the fact that these populations have wider ranges of acceptable temperatures. The differences in development of C. maxillosus between the studies could be also due to a number of other factors, e.g., differences in beetle diets or differences in rearing conditions. It is difficult to compare such research because of the large differences of the methods used. However, such comparisons reveal that standardization of the insect rearing protocols seems to be one of the most pressing needs in forensic entomology.

Size of pupae and emerging adult beetles was inversely related to temperature. Starting from $17.5^{\circ} \mathrm{C}$, pupae and adult beetles became smaller. Similarly, larval size decreased with temperature starting from $15^{\circ} \mathrm{C}$. These findings are consistent with the temperature-size rule ("hotter is smaller") and represent a form of phenotypic plasticity commonly occurring in ectotherms [19].

As expected, the food type influenced the development of C. maxillosus. First- and second-instar larvae of the beetles fed

Table 3 Length and weight (mean (SE; $N$ ) of $C$. maxillosus reared at $24{ }^{\circ} \mathrm{C}$ fed with different types of food. Means were calculated based on the length and weight measurements conducted at the beginning of particular stage

\begin{tabular}{lcllll}
\hline Food type & 3rd-instar length & 3rd-instar weight & Pupal weight & Adult length at emergence & Adult weight at emergence \\
\hline Calliphora sp. larvae & $20.08(0.2 ; 24)$ & $65.75(2.38 ; 24)$ & $174.72(4.28 ; 23)$ & $20.38(0.28 ; 21)$ & $149.52(3.61 ; 21)$ \\
Calliphora sp. puparia & $20.68(0.26 ; 17)$ & $71.17(3.9 ; 17)$ & $184.86(9.12 ; 16)$ & $20.66(0.37 ; 16)$ & $160.1(8.84 ; 16)$ \\
Lucilia sp. larvae & $20.6(0.21 ; 20)$ & $69.63(1.96 ; 20)$ & $176.24(4.08 ; 20)$ & $20.35(0.28 ; 17)$ & $149.01(3.84 ; 17)$ \\
Lucilia sp. puparia & $19.29(0.23 ; 14)$ & $59.71(1.76 ; 14)$ & $169.67(4.25 ; 14)$ & $20.65(0.25 ; 13)$ & $145.11(4.42 ; 13)$ \\
Necrodes littoralis larvae & $16.07(0.18 ; 15)$ & $28.19(0.97 ; 15)$ & $58.6(15.75 ; 2)$ & - & - \\
\hline
\end{tabular}



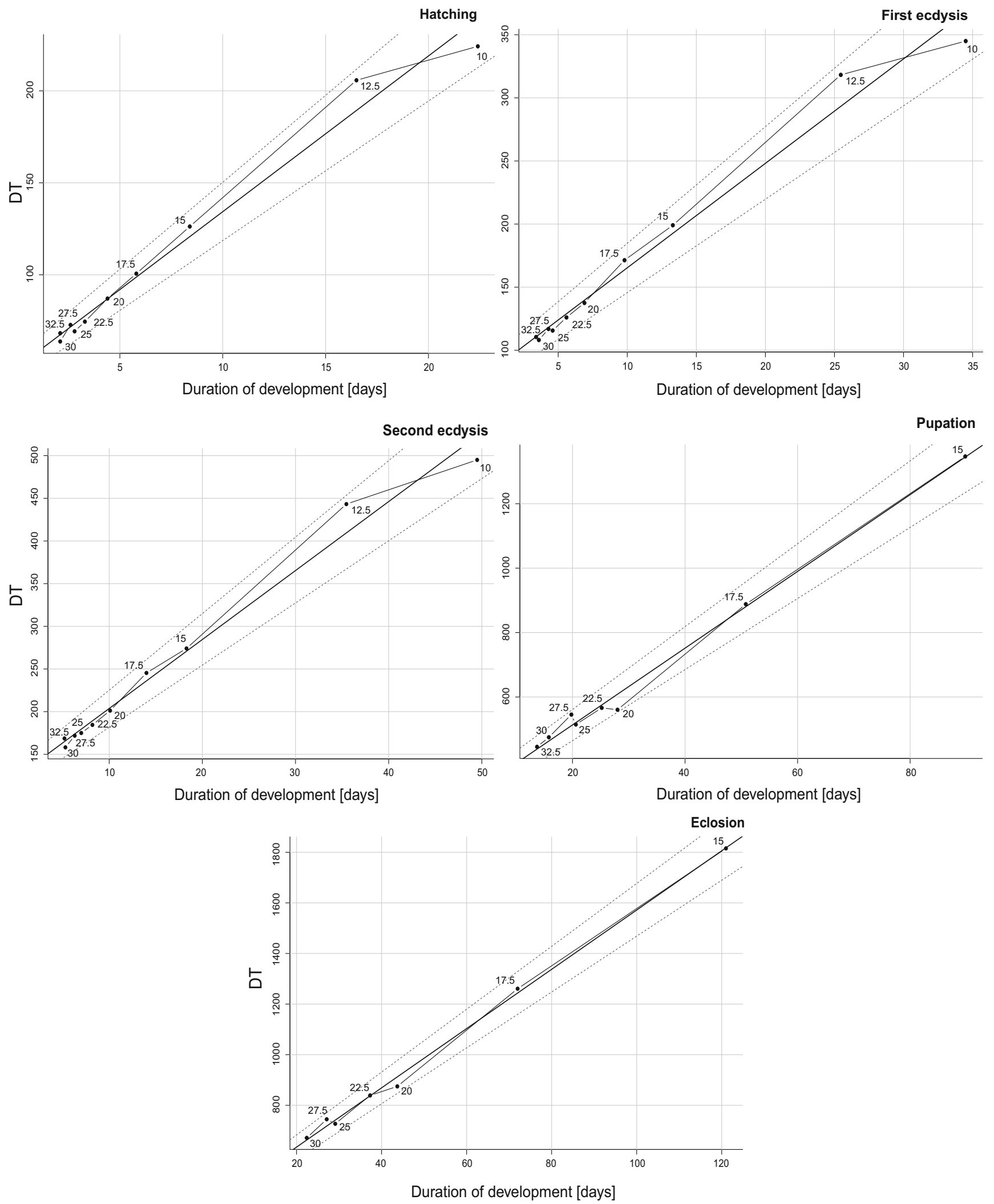

Fig. 5 Reduced major axis (RMA) regression lines sensu Ikemoto and Takai [10] with 95\% confidence intervals were used to determine thermal constants for five developmental events; DT is the time in days to reach the adult stage multiplied by the constant rearing temperature 
Table 4 Thermal summation models for five developmental events of C. maxillosus calculated using Ikemoto and Takai [10] method

\begin{tabular}{lllllll}
\hline & Model & Temp. range & $N$ & Thermal summation constant $K(\mathrm{SE})$ & Developmental threshold $D_{0}(\mathrm{SE})$ & $r^{2}$ \\
\hline Hatching & $\mathrm{DT}=49.225+8.506 \times \mathrm{D}$ & $10-32.5$ & 10 & $49.225(4.009)$ & $8.506(0.415)$ & 0.981 \\
First ecdysis & $\mathrm{DT}=81.688+8.314 \times \mathrm{D}$ & $10-32.5$ & 10 & $81.688(6.033)$ & $8.314(0.402)$ & $0.085(0.365)$ \\
Second ecdysis & $\mathrm{DT}=122.883+8.085 \times \mathrm{D}$ & $10-32.5$ & 10 & $122.883(7.80)$ & $11.984(0.351)$ & $11.660(0.243)$ \\
Pupation & $\mathrm{DT}=274.825+11.984 \times \mathrm{D}$ & $15-32.5$ & 8 & $274.825(14.49)$ & 0.984 \\
Eclosion & $\mathrm{DT}=405.156+11.660 \times \mathrm{D}$ & $15-30$ & 7 & $405.156(14.63)$ & 0.995 \\
\hline
\end{tabular}

Table 5 Estimated parameters and goodness of fit (AICc) of the SSI model for five developmental events of C. maxillosus

\begin{tabular}{lccccc}
\hline Parameter & Hatching & First ecdysis & Second ecdysis & Pupation & Eclosion \\
\hline$\rho_{\varphi}$ & 0.213748 & 0.1312873 & 0.08648179 & 0.032643 & 19132.11 \\
$\Delta H_{\mathrm{A}}$ & 19260.18 & 18671.95 & 18005.09 & 18217.24 & -73724.8 \\
$\Delta H_{\mathrm{L}}$ & -52357.1 & -51441.47 & -53625.17 & -77343.7 & 52283.35 \\
$\Delta H_{\mathrm{H}}$ & 41899.41 & 40602.36 & 40045.81 & 20.9551 & 20.5736 \\
$T_{\varphi}$ & 19.0278 & 19.0387 & 18.7123 & 11.9839 & 11.6601 \\
$T_{\mathrm{L}}$ & 8.506 & 8.3141 & 3.0852 & 35.0283 & 32.906 \\
$T_{\mathrm{H}}$ & 32.3455 & -19.78 & -27.9 & -34.9725 & -35.48 \\
$A I C c$ & -9.85 & 0.99687 & 0.9936287 & 0.965429 & 0.981282 \\
$r^{2}$ & 0.9946 & & & & \\
\hline
\end{tabular}

$\rho_{\varphi}-$ mean development rate at the intrinsic optimum temperature (1/day)

$\Delta H_{\mathrm{A}}$ - enthalpy of activation of the reaction that is catalyzed by the enzyme (cal/mol)

$\Delta H_{\mathrm{L}}$ - change in enthalpy associated with low temperature inactivation of the enzyme (cal/mol)

$\Delta H_{\mathrm{H}}$ change in enthalpy associated with high temperature inactivation of the enzyme (cal/mol)

$T_{\varphi}$-intrinsic optimum temperature at which no enzyme inactivation is hypothesized $\left({ }^{\circ} \mathrm{C}\right)$

$T_{\mathrm{L}}$ - temperature at which the enzyme is $1 / 2$ active and $1 / 2$ low temperature inactive $\left({ }^{\circ} \mathrm{C}\right)$

$T_{\mathrm{H}}$-temperature at which the enzyme is $1 / 2$ active and $1 / 2$ high temperature inactive $\left({ }^{\circ} \mathrm{C}\right)$

with $N$. littoralis larvae developed significantly longer than larvae fed with other diets. Additionally, no specimen reached the adult stage when fed with Necrodes littoralis larvae. These results indicate that in natural and typical conditions, C. maxillosus larvae do not prey on larval Necrodes littoralis. When larvae were fed with blowfly larvae, the highest mortality was observed at the beetle pupal stage (Fig. 3). However, for $C$. maxillosus larvae fed with blowfly puparia, the highest mortality was observed at the first larval stage of $C$. maxillosus (Fig. 3). Probably, only some of the first-instar larvae were able to puncture the blowfly puparium, and for this reason, beetle mortality at this stage was so high. These findings indicate that $C$. maxillosus may change food preferences during its development. First-instar larvae may feed on blowfly larvae only, while second- and third-instar larvae may switch to a more diverse diet, with larger contribution of blowfly puparia. These patterns are actually consistent with successional patterns of blowflies and $C$. maxillosus as recorded on pig carcasses [57].

Current linear models are useful for minimum PMI estimation in Central Europe. The thermal constant $K$ for the total development time was lower than that in Wang et al.'s study [45] (405.16 \pm 14.63 and $492.06 \pm 23.61^{\circ}$ days, respectively). Lower developmental threshold $\left(T_{\min }\right)$ was however higher than the one presented by Wang et al. [45] $\left(11.6 \pm 0.24{ }^{\circ} \mathrm{C}\right.$ and $9.6 \pm 0.58{ }^{\circ} \mathrm{C}$, respectively). Due to the lower $T_{\min }$ for C. maxillosus from China, it should logically take longer to reach the adult stage. These differences may therefore result from differences in thermal requirements of the Chinese and Central European populations of the beetle. However, lower developmental threshold for the Chinese population of C. maxillosus might have been underestimated due to the poor representation of the low temperatures in this study (i.e., 17.5$\left.32.5^{\circ} \mathrm{C}\right)$.

Fig. 6 SSI models for five developmental events of $C$. maxillosus. Black circles represent observed developmental rates at particular rearing temperatures; open squares denote the predicted development rates at temperature at which the enzyme is $1 / 2$ active and $1 / 2$ low temperature inactive $\left({ }^{\circ} \mathrm{C}\right)\left(T_{\mathrm{L}}\right)$, intrinsic optimum temperature at which no enzyme inactivation is hypothesized $\left({ }^{\circ} \mathrm{C}\right)\left(T_{\varphi}\right)$, and temperature at which the enzyme is $1 / 2$ active and $1 / 2$ high temperature inactive $\left({ }^{\circ} \mathrm{C}\right)\left(T_{\mathrm{H}}\right)$ 
Int J Legal Med (2020) 134:1531-1545

1541
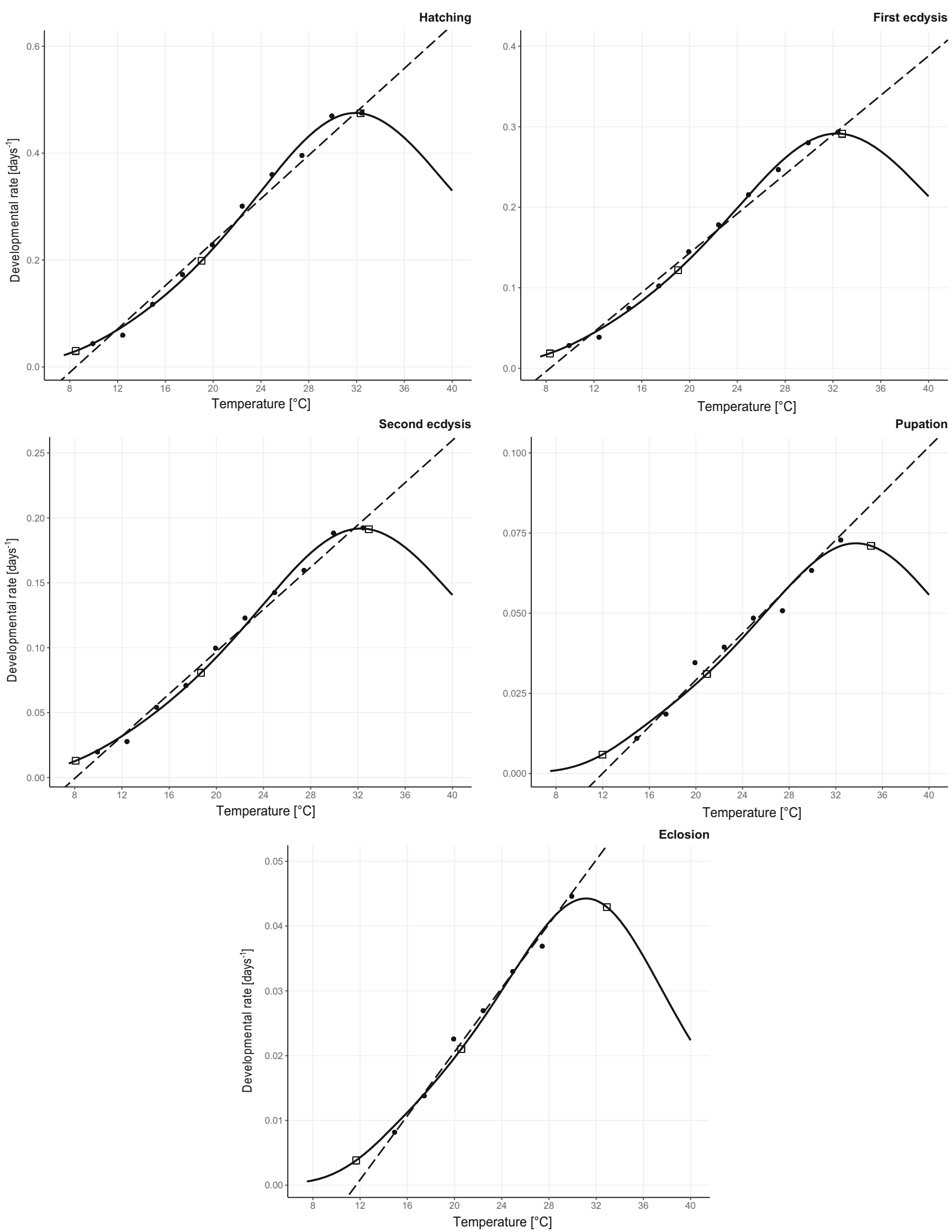

炟 Springer 
Fig. 7 Relative error of age estimation for C. maxillosus validation specimens (reared at ten constant temperatures) using thermal summation data from our Table 4

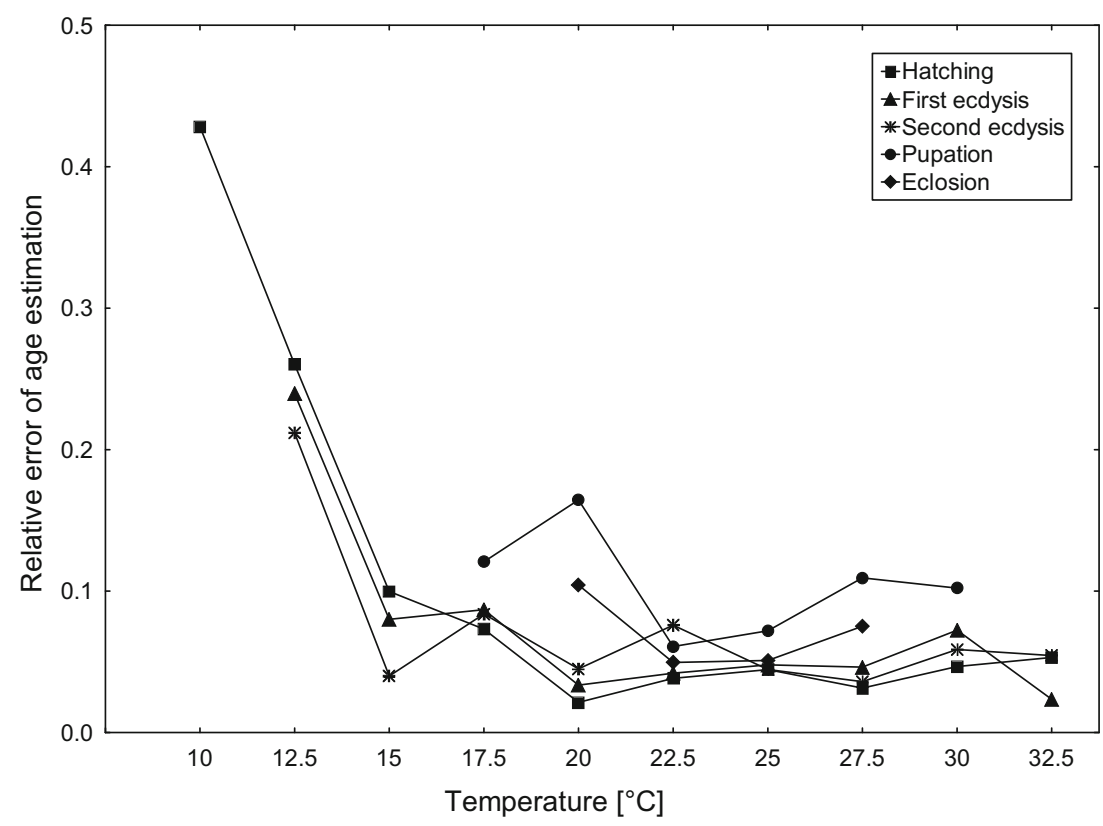

In our study, $T_{\min }$ and $T_{\max }$ for pupation and eclosion obtained from nonlinear models (Analytis, Brière-2, and Lactin2) were not satisfactory, since some of them represented biologically unrealistic values (see Online Resource 1), e.g., very low values for $T_{\min }$, some even below $0{ }^{\circ} \mathrm{C}$ (see Online Resource 1). Our fit of nonlinear models was biased in the region close to upper development rate limits. On the other hand, in the similar study on Fannia canicularis (Linnaeus) (Diptera: Fanniidae) [17], nonlinear models were biased in the area of lower development rate limits. Because of the high mortality of $C$. maxillosus in the highest examined temperatures, data used for nonlinear modeling represented a rather straight line and, in consequence, led to a failure in nonlinear model fitting. Estimating lower and upper thermal thresholds with the use of empirical nonlinear models, e.g., the Analytis, Brière-2, or Lactin-2, may not provide reliable results [59]. Application of nonlinear models to determine thermal tolerance of forensically useful insects, i.e., the temperature range between the minimum and the maximum rate of development is therefore not a useful approach. Simpler linear models provide more reliable estimations of $T_{\min }$ and additionally allow estimating $K$, a constant of primary usefulness for forensic practice. On the other hand, the theoretical SSI model may provide forensically useful information on the development of examined insect species [59].
Fig. 8 Relative error of age estimation for C. maxillosus validation specimens reared at $24^{\circ} \mathrm{C}$ and fed with different food types. Thermal summation data from Table 4 were used for the estimation

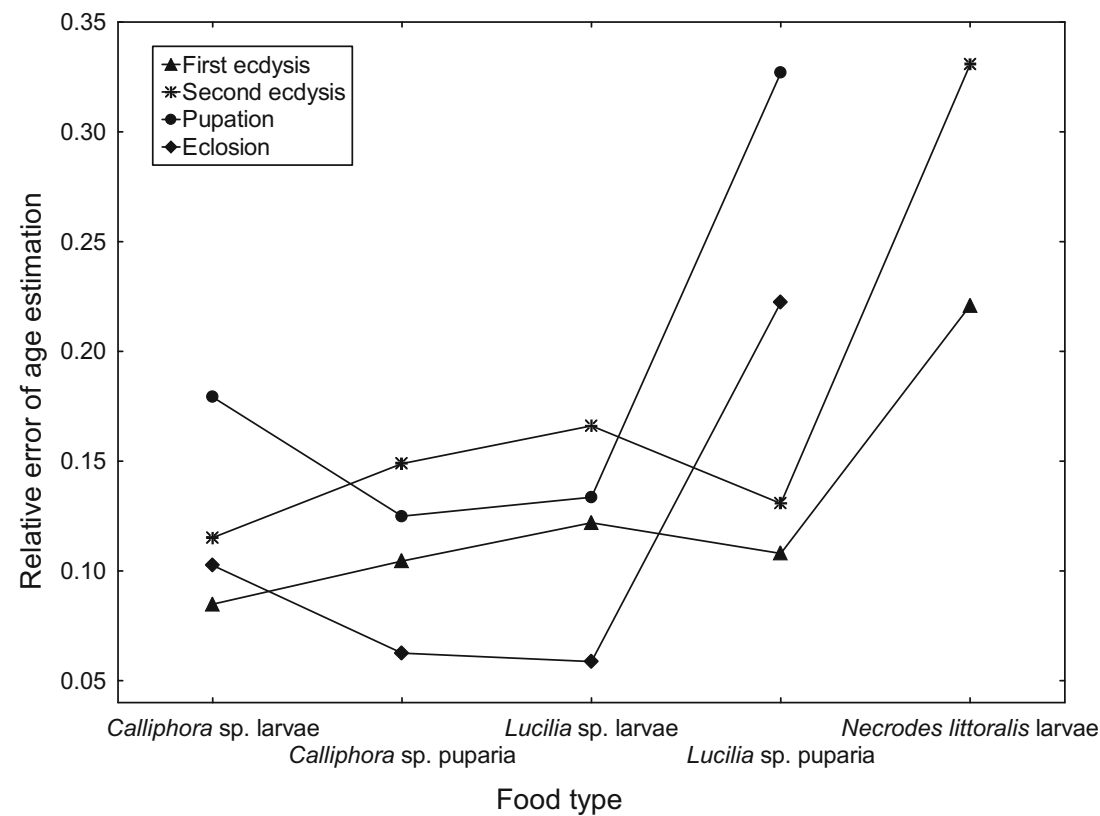


Environmental conditions used in reference developmental studies are rarely the same as those experienced during casework. Thus, accuracy of lab-generated data should be determined preferably in a robust validation study. Validation part of this study revealed that accuracy in age estimation was lower using models for final development landmarks, i.e., pupation or eclosion than models for earlier events. Interestingly, age estimation errors were the largest while using model for pupation (Fig. 7). This may be due to the large variation in duration of the third larval stage resulting from surprisingly high variation in the postfeeding larval phase (Table 1).

Because the food type influenced the development of C. maxillosus similarly, it must have affected the accuracy of age estimation for specimens reared on different diets. Developmental models were created based on specimens fed with Calliphora sp. larvae. When models were validated using specimens fed with the same type of food and in the same laboratory trials, error rates were below $10 \%$ for all developmental events (see data for 22.5 and $25{ }^{\circ} \mathrm{C}$ in Fig. 7). However, when we used specimens fed with different diets and reared under $24{ }^{\circ} \mathrm{C}$ in different trials, error rates were generally larger (usually between 10 and $15 \%$ ), and for some diets, they were very much larger, e.g., $32 \%$ for pupation and $22 \%$ for eclosion for larvae fed with Lucilia sp. puparia (Fig. 8). As for the fly-related diets, total development times were the shortest (Table 3), mortality was the highest (Fig. 3), beetle size was the smallest (Table 4), and estimation errors were the largest (Fig. 8) for C. maxillosus fed with Lucilia puparia. These findings indicate that in natural and typical conditions, larvae of C. maxillosus do not prey solely on Lucilia puparia, probably due to the low quality of this diet. Some studies suggest that food quality affects thermal constants in insects [60-62]. Additionally, Jarošík et al. [60] showed that aphidophagous ladybirds develop significantly faster and start developing at significantly lower temperature on a goodquality diet. Consequently, the food quality may affect lower development threshold, indicating that the threshold may change depending on a diet. Similar results were reported for moths [61, 62] and aphids [63]. It is therefore possible that similar effects may occur in case of C. maxillosus and other forensically useful insects. In natural conditions, carrion insects usually have access to optimal diet. Therefore, insect evidences encountered in casework are usually specimens fed with optimal food type. However, the problem may arise when we estimate their age with developmental data obtained using non-optimal diet. This source of estimation error may be particularly important in case of predatory insects, as was demonstrated in this article for predatory $C$. maxillosus beetle. Moreover, these findings indicate that collecting reference developmental data using optimal diet is crucial and that forensic entomologists should pay more attention to the quality of food used in developmental studies and in rearing insects during casework.
Funding information The study was funded by the Ministry of Science and Higher Education (grant no. DI2013011043).

\section{Compliance with ethical standards}

Conflict of interest The authors declare that they have no conflict of interest.

Ethical approval The current study involved laboratory experiments using insect species Creophilus maxillosus (Coleoptera: Staphylinidae). The species is not under protection. No permissions or approval from Ethic Commission were needed.

Informed consent Not applicable.

Open Access This article is licensed under a Creative Commons Attribution 4.0 International License, which permits use, sharing, adaptation, distribution and reproduction in any medium or format, as long as you give appropriate credit to the original author(s) and the source, provide a link to the Creative Commons licence, and indicate if changes were made. The images or other third party material in this article are included in the article's Creative Commons licence, unless indicated otherwise in a credit line to the material. If material is not included in the article's Creative Commons licence and your intended use is not permitted by statutory regulation or exceeds the permitted use, you will need to obtain permission directly from the copyright holder. To view a copy of this licence, visit http://creativecommons.org/licenses/by/4.0/.

\section{References}

1. Wigglesworth VB (1972) The principles of insect physiology, 7th edn. Chapman and Hall, New York

2. Higley LG, Haskell NH (2010) Insect development and forensic entomology. In: Byrd JH, Castner JL (eds) Forensic entomology. The utility of arthropods in legal investigations. CRC Press, Boca Raton, pp 389-407

3. Sharpe PJH, DeMichele DW (1977) Reaction kinetics of poikilotherm development. J Theor Biol 64(4):649-670

4. Pollard CP (2015) A temperature-dependent development model for willow beetle species (Coleoptera: Chrysomelidae) in Ireland: simulation of phenology/voltinism in response to climate change. $\mathrm{PhD}$ thesis, National University of Ireland Maynooth

5. Dixon AFG, Alois Honěk A, Keil P, Kotela MAA, Šizling AL, Jarošík V (2009) Relationship between the minimum and maximum temperature thresholds for development in insects. Funct Ecol 23(2):257-264

6. Amendt J, Richards CS, Campobasso CP, Zehner R, Hall MJ (2011) Forensic entomology: applications and limitations. Forensic Sci Med Pathol 7(4):379-392

7. Frątczak-Łagiewska K, Matuszewski S (2018) Sex-specific developmental models for Creophilus maxillosus (L.) (Coleoptera: Staphylinidae): searching for larger accuracy of insect age estimates. Int J Legal Med 132(3):887-895

8. Fratczak-Łagiewska K, Matuszewski S (2019) The quality of developmental reference data in forensic entomology: detrimental effects of multiple, in vivo measurements in Creophilus maxillosus L. (Coleoptera: Staphylinidae). Forensic Sci Int 298:316-322

9. Roe A, Higley LG (2015) Development modeling of Lucilia sericata (Diptera: Calliphoridae). PEERJ 3(803):1-14 
10. Ikemoto T, Takai K (2000) A new linearized formula for the law of total effective temperature and the evaluation of line-fitting methods with both variables subject to error. Environ Entomol 29:671-682

11. Richards CS, Crous KL, Villet M (2009) Models of development for blowfly sister species Chrysomya chloropyga and Chrysomya putoria. Med Vet Entomol 23(1):56-61

12. Richards CS, Paterson ID, Villet MH (2008) Estimating the age of immature Chrysomya albiceps (Diptera: Calliphoridae), correcting for temperature and geographical latitude. Int J Legal Med 122(4): 271-279

13. Ridgeway JA, Midgley JM, Collett IJ, Villet MH (2013) Advantages of using development models of the carrion beetles Thanatophilus micans (Fabricius) and T. mutilatus (Castelneau) (Coleoptera: Silphidae) for estimating minimum post mortem intervals, verified with case data. Int J Legal Med 128(1):207-220

14. Midgley JM, Villet MH (2009) Development of Thanatophilus micans (Fabricius 1794) (Coleoptera: Silphidae) at constant temperatures. Int J Legal Med 123(4):285-292

15. Wang Y, Li L, Wang J, Wang M, Yang L, Tao L, Zhang Y, Hou Y, Chu J, Hou Z (2016) Development of the green bottle fly Lucilia illustris at constant temperatures. Forensic Sci Int 267:136-144

16. Wang Y, Yang L, Zhang Y, Tao L, Wang J (2018) Development of Musca domestica at constant temperatures and the first case report of its application for estimating the minimum postmortem interval. Forensic Sci Int 285:172-180

17. Grzywacz A (2019) Thermal requirements for the development of immature stages of Fannia canicularis (Linnaeus) (Diptera: Fanniidae). Forensic Sci Int 297:16-26

18. Zuha RM, Omar B (2014) Development rate, size, and sexual dimorphism of Megaselia scalaris (Loew) (Diptera: Phoridae): its possible implications in forensic entomology. Parasitol Res 113: 2285-2294

19. Voss SC, Cook DF, Hung WF, Dadour IR (2014) Survival and development of the forensically important blow fly, Calliphora varifrons (Diptera: Calliphoridae) at constant temperatures. Forensic Sci Med Pathol 10(3):314-321

20. Marchenko MI (2001) Medicolegal relevance of cadaver entomofauna for the determination of the time of death. Forensic Sci Int 120:89-109

21. Harnden LM, Tomberlin JK (2016) Effects of temperature and diet on black soldier fly, Hermetia illucens (L.) (Diptera: Stratiomyidae), development. Forensic Sci Int 266:109-116

22. Núñez-Vázquez C, Tomberlin JK, Cantú-Sifuentes M, GarcíaMartínez O (2013) Laboratory development and field validation of Phormia regina (Diptera: Calliphoridae). J Med Entomol 50(2):252-260

23. Tarone AM, Foran DR (2008) Generalized additive models and Lucilia sericata growth: assessing confidence intervals and error rates in forensic entomology. J Forensic Sci 53(4):942-948

24. Mohr RM, Tomberlin JK (2015) Development and validation of a new technique for estimating a minimum postmortem interval using adult blow fly (Diptera: Calliphoridae) carcass attendance. Int $\mathbf{J}$ Legal Med 129(4):851-859

25. VanLaerhoven SL (2008) Blind validation of postmortem interval estimates using developmental rates of blow flies. Forensic Sci Int 180(2-3):76-80

26. Richards CS, Villet MH (2008) Factors affecting accuracy and precision of thermal summation models of insect development used to estimate post-mortem intervals. Int J Legal Med 122(5):401-408

27. Bong L-J, Neoh K-B, Lee C-Y, Jaal Z (2014) Effect of diet quality on survival and reproduction of adult Paederus fuscipes (Coleoptera: Staphylinidae). J Med Entomol 51(4):752-759

28. Warren JA, Anderson GS (2009) A comparison of development times for Protophormia terraenovae (R-D) reared on different food substrates. Can Soc Forensic Sci J 42(3):161-171
29. Kaneshrajah G, Turner B (2004) Calliphora vicina larvae grow at different rates on different body tissues. Int J Legal Med 118(4): 242-244

30. Clark K, Evans L, Wall R (2006) Growth rates of the blowfly, Lucilia sericata, on different body tissues. Forensic Sci Int 156(23):145-149

31. Bernhardt V, Schomerus C, Verhoff MA, Amendt J (2017) Of pigs and men-comparing the development of Calliphora vicina (Diptera: Calliphoridae) on human and porcine tissue. Int J Legal Med 131(3):847-853

32. Thomas J, Sanford MR, Longnecker M, Tomberlin JK (2016) Effects of temperature and tissue type on the development of Megaselia scalaris (Diptera: Phoridae). J Med Entomol 53(3): 519-525

33. Thompson S (1999) Nutrition and culture of entomophagous insects. Ann Rev Entomol 44:561-592

34. Mirhosseini MA, Hosseini MR, Jalali MA (2015) Effects of diet on development and reproductive fitness of two predatory coccinellids (Coleoptera: Coccinellidae). Eur J Entomol 112(3):446-452

35. Byrd JH, Castner JL (2010) Insects of forensic importance. In: Byrd $\mathrm{JH}$, Castner JL (eds) Forensic entomology. The utility of arthropods in legal investigations. CRC Press, Boca Raton, pp 39-129

36. Smith KG (1986) A manual of forensic entomology. The trustees of British Museum, London

37. Watson-Horzelski EJ, Clark-Aguilard AC (2011) Predatory behaviors of Creophilus maxillosus (L.) (Coleoptera: Staphylinidae) towards the invasive blow fly Chrysomya rufifacies (Macquart) (Diptera: Calliphoridae). Coleopts Bull 65(2):177-181

38. Matuszewski S (2012) Estimating the preappearance interval from temperature in Creophilus maxillosus L. (Coleoptera: Staphylinidae). J Forensic Sci 57(1):136-145

39. Matuszewski S, Mądra-Bielewicz A (2016) Validation of temperature methods for the estimation of pre-appearance interval in carrion insects. Forensic Sci Med Pathol 12:50-57

40. Mądra-Bielewicz A, Frątczak-Łagiewska K, Matuszewski S (2017) Sex- and size-related patterns of carrion visitation in Necrodes littoralis (Coleoptera: Silphidae) and Creophilus maxillosus (Coleoptera: Staphylinidae). J Forensic Sci 62(5):1229-1233

41. Matuszewski S, Fratczak K, Konwerski S, Bajerlein D, Szpila K, Jarmusz M, Szafałowicz M, Mądra A (2016) Effect of body mass and clothing on carrion entomofauna. Int J Legal Med 130(1):221232

42. Voris R (1939) The immature stages of the genera Ontholestes, Creophilus and Staphylinus, Staphylinidae (Coleoptera). Ann Entomol Soc Am 32:288-303

43. Krammer S (1954) Notes and observations on the biology and rearing of Creophilus maxillosus (L.) (Coleoptera, Staphylinidae). Ann Entomol Soc Am 48(5):375-380

44. Watson-Horzelski EJ (2012) Survival and time of development for Creophilus maxillosus (L.) (Coleoptera: Staphylinidae) at three constant temperatures. Coleopt Bull 66(4):365-370

45. Wang Y, Yang JB, Wang JF, Li LL, Wang M, Yang LJ, Tao LY, Chu J, Hou YD (2017) Development of the forensically important beetle Creophilus maxillosus (Coleoptera: Staphylinidae) at constant temperatures. J Med Entomol 54(2):281-289

46. Gallagher MB, Sandhu S, Kimsey R (2010) Variation in developmental time for geographically distinct populations of the common green bottle fly, Lucilia sericata (Meigen). J Forensic Sci 55(2): 438-442

47. Matuszewski S, Frątczak-Łagiewska K (2018) Size at emergence improves accuracy of age estimates in forensically-useful beetle Creophilus maxillosus L. (Staphylinidae). Sci Rep 5(1):2390

48. Analytis S (1981) Relationship between temperature and development times in phytopathogenic fungus and in plant pests: a mathematical model. Agric Res 5:133-159 
49. Brière JF, Pracros P, Le Roux AY, Pierre JS (1999) A novel rate model of temperature-dependent development for arthropods. Environ Entomol 28(1):22-29

50. Lactin DJ, Holliday NJ, Johnson DL, Craigen R (1995) Improved rate of temperature dependent development by arthropods. Environ Entomol 24:68-75

51. Shi P, Ikemoto T, Egami C, Sun Y, Ge F (2011) A modified program for estimating the parameters of the SSI model. Environ Entomol 40(2):462-469

52. Legendre P (2018) lmodel2 version 1.7-3. https://cran.r-project. org/pack-age=lmodel2. Accessed 16 June 2019

53. Shamakhi L, Zibaee A, Karimi-Malati A, Hoda H (2018) A laboratory study on the modeling of temperature-dependent development and antioxidant system of Chilo suppressalis (Lepidoptera: Crambidae). J Insect Sci 18(2):1-11

54. Arbab A, Kontodimas DC, Mcneill MR (2008) Modeling embryo development of Sitona discoideus Gyllenhal (Coleoptera: Curculionidae) under constant temperature. Environ Entomol 37(6):1381-1388

55. Roy M, Brodeur J, Cloutier C (2002) Relationship between temperature and developmental rate of Stethorus punctillum (Coleoptera: Coccinellidae) and its prey Tetranychus mcdanieli (Acarina: Tetranychidae). Environ Entomol 31(1):177-187

56. Elzhov TV, Mullen A-N, Spiess KM, Ben B (2016) minpack.lm version 1.2-1. https://cran.r-project.org/package=minpack. $1 \mathrm{~m}$. Accessed 16 June 2019

57. Matuszewski S, Bajerlein D, Konwerski S, Szpila K (2011) Insect succession and carrion decomposition in selected forests of Central
Europe. Part 3: succession of carrion fauna. Forensic Sci Int 207(13):150-163

58. Szpila K (2010) Key for the identification of third instars of European blowlfies (Diptera: Calliphoridae) of forensic importance. In: Amendt J, Campobasso CP, Goff ML, Grassberger M (eds) Current concepts in forensic entomology. Springer, Dordrecht, pp 43-56

59. Ikemoto T, Kiritani K (2019) Novel method of specifying low and high threshold temperatures using thermodynamic SSI model of insect development. Environ Entomol 48(3):479-488

60. Jarošík V, Kumarc G, Omkarc DAFG (2014) Are thermal constants constant? A test using two species of ladybird. J Therm Biol 40:1-8

61. Taylor MFJ (1988) Field measurements of the dependence of lifehistory on plant nitrogen and temperature for a herbivorous moth. J Anim Ecol 57:873-891

62. Honěk A, Jarošík V, Martinková Z, Novák I (2002) Food induced variation of thermal constants of development and growth of Autographa gamma (Lepidoptera: Noctuidae) larvae. Eur J Entomol 99:241-252

63. Dixon AFG, Honěk A, Jarošík V (2013) Physiological mechanisms governing slow and fast development in predatory ladybirds. Physiol Entomol 38:26-32

Publisher's note Springer Nature remains neutral with regard to jurisdictional claims in published maps and institutional affiliations. 